\title{
IJMF 10th anniversary - advances in material forming
}

\section{Francisco Chinesta ${ }^{1}$}

Published online: 1 September 2020

(C) Springer-Verlag France SAS, part of Springer Nature 2020

The International Journal of Material Forming -IJMF- was celebrating its 10th anniversary in 2018. With is first issue published in 2008, IJMF continues being a key figure in the science and technology of material forming, covering different approaches (modeling, simulation and experiments), materials (including composites) and forming processes.

The journal, published by Springer, was from its origin, the official journal of the ESAFORM association, and both are progressing and adapting to the evolving environment in very close connection.

Ten years is little in the scale of industrial manufacturing processes, but the last ten years were rich because of many scientific and technological irruptions, in particular the socalled 4th industrial revolution. The first was associated to the use of the water steam in production; the second replaced the water steam by electricity with its induced massive production; in the third, electronics and information irrupted, with the associate automation. Now, the four, with the third one as foundation, represents the digital revolution.

The new protagonists are the IoT, the data (big or smart), the tools for manipulating them based on artificial intelligence, the continuum computing (very soon integrating the quantum computing into the loop), new mathematical technologies for manipulating faster and better the existing knowledge (physics-based mathematical models), ... and their consequences were immediate: new engineered materials, inversion of classical workflow: material, process, structure and performances; in the smartest one: performances, structure, process and materials (additive manufacturing and 3D printing is a direct consequence of this general movement), digital and hybrid twins representing a component, a system, a process, ... in operation all along its life, to better adapt, anticipate, ...

Very probably all these new paradigms will pave the next ten years, may be more, of the IJMF, but certainly, the future will embrace the past, the future should enrich instead of replace the vast amount of existing knowledge, and in that case we can ensure that there is room for advances in the most traditional topics of material forming, for better describe materials during their transformations, to better model materials and processes of great industrial interest (e.g. high-rate processing of composites) but poorly understood, mastering new welding processes, or use collected data to improve quality and efficiency, as this first anniversary issue will address.

This issue will also include three review papers as well as two letters to the editor related to a recent published paper.

Francisco Chinesta Editor in Chief of IJMF

Publisher's note Springer Nature remains neutral with regard to jurisdictional claims in published maps and institutional affiliations.
Francisco Chinesta

Francisco.CHINESTA@ensam.eu

1 Arts et Metiers Institute of Technology, Paris, France 